\title{
Prevalence of Enteroparasites Among Non-Saudis in Bahrah, Saudi Arabia
}

Majed H. Wakid ${ }^{1,2}$

1. Medical Laboratory Technology, Faculty of Applied Medical Sciences, King Abdulaziz University, Jeddah, SAU 2. Special Infectious Agents Unit, King Fahd Medical Research Center, Jeddah, SAU

Corresponding author: Majed H. Wakid, mwakid@kau.edu.sa

\section{Abstract \\ Background}

Enteroparasitic infections in tropical and subtropical regions of the world are among the most common diseases. The majority of the cases may show no symptoms; however, many untreated cases may experience severe complications. The recent substantial economic development in Saudi Arabia has resulted in an inflow of millions of workers with intestinal parasitic infection, from highly endemic countries, mainly from Asia and Africa.

\section{Objective}

This cross-sectional study aimed to assess for the first time the prevalence and associated factors of intestinal parasitic infestation among non-Saudi residents in Bahrah, western region, Saudi Arabia.

\section{Materials and methods}

A total of 355 stool samples were collected from participants included in this study for several examinations of intestinal parasites. In addition, questionnaires including personal data, sociodemographic data, personal hygiene, health habits and other factors were used.

\section{Results}

The prevalence of intestinal parasitic infections among non-Saudi workers in the present study was $22.3 \%$, and the prevalence of protozoan infection was higher than helminth infection. Most of the workers were from Asian countries and were prevalent with Trichuris trichiura, Blastocystis hominis, Endolimax nana and Ascaris lumbricoides. Single intestinal infections were among $86 \%$ of the infected cases. The main significant factors associated with intestinal parasitic infections were personal hygiene practices (such as proper handwashing before meals and after using the toilet), source of drinking water and type of living accommodation.

Received 06/29/2020 Review began 07/01/2020 Review ended 07/03/2020 Published 07/18/2020

๑) Copyright 2020 Wakid. This is an open access article distributed under the terms of the Creative Commons Attribution License CC-BY 4.0., which permits unrestricted use, distribution, and reproduction in any medium, provided the original author and source are credited.

\section{Conclusion}

Intestinal parasites were slightly more prevalent among non-Saudi workers in Bahrah. There is a need for public health awareness programs to prevent spreading of the infections.

Categories: Infectious Disease, Public Health, Epidemiology/Public Health Keywords: intestinal, parasites, bahrah, saudi arabia, prevalence, risk factors

\section{Introduction}

Infections with intestinal parasites are among the common neglected diseases in many tropical and subtropical regions of the world [1]. These organisms can live, replicate or cause clinical manifestations in the human gastrointestinal system. Globally, the World Health Organization estimated that $24 \%$ of the world's population is infected with soil-transmitted helminth, while more than three billion have no symptoms and over 800 million children are at risk of infection. The intestinal parasitic infection can lead to many severe complications such as malnutrition, growth retardation, several types of anemia, cancer, poor school performance and other problems [2,3]. Most of the intestinal parasites are transmitted mainly among communities with low socioeconomic condition due to poor sanitation and hygiene practices, contaminated food, water and soil. Saudi Arabia's climate is hot most of the year. In addition, many workers in Bahrah are non-Saudis from Asian and African countries, where tropical diseases including enteroparasitic infections are prevalent.

Bahrah is a town in Makkah Province, in the western region of Saudi Arabia, and is located between Makkah and Jeddah. Its population in 2017 according to the General Authority for Statistics was 96,646, of which $71 \%$ were Saudis and $29 \%$ were non-Saudis (25\% males and $4 \%$ females) [4]. 
The present study was conducted to determine for the first time the prevalence and risk factors of intestinal parasites among non-Saudi people living in Bahrah, Saudi Arabia.

\section{Materials And Methods \\ Study design and sample collection}

This cross-sectional study was conducted for a six-month period (March to August 2019) in Bahrah town of the western region of Saudi Arabia. A total of 500 participants were provided with a labeled, clean plastic stool sample collector and instructions for collection. Each one was provided with a consent form and a questionnaire related to personal data, sociodemographic data, health and awareness about intestinal parasites. All samples related to incomplete forms or with insufficient quantity were excluded.

\section{Parasitological analysis of the samples}

Sample analysis included gross examination to check for color, consistency, presence of macroscopic blood, mucous, adult worms (of Ascaris lumbricoides and Enterobius vermicularis) or gravid segments of Taenia species.

In addition, stool samples were prepared and examined by different techniques including the direct smears, sedimentation method, trichrome staining and modified Kinyoun's staining. All wet smears were examined using 10x and 40x objective lenses, while permanently stained smears were examined using the oil immersion objective lens.

Direct smears were prepared by emulsifying $2 \mathrm{mg}$ of stool with saline and iodine on a glass microscope slide $[5,6]$. Sedimentation technique was performed as described in previous studies with slight modification: 2-3 $\mathrm{g}$ of stool sample was emulsified in $10 \mathrm{ml}$ of $10 \%$ formal-saline and left for 30 minutes [5,7]. Preserved stool was then passed through two layers of gauze, centrifuged at $2000 \mathrm{rpm}$ for 10 minutes and the supernatant was disposed of. In case of unclear supernatant, the washing step was repeated. The sediment was resuspended in $10 \mathrm{ml}$ formal saline $(10 \% \mathrm{v} / \mathrm{v}), 3 \mathrm{ml}$ of diethyl ether was dispensed and shaken vigorously for 20 seconds and then centrifuged at $2000 \mathrm{rpm}$ for 10 minutes. The sediment was mixed with two drops of iodine and then examined under a light microscope. Para-Pak ${ }^{\circledR}$ (Meridian Bioscience, Germany) trichrome stain was used and performed based on the manufacturer's procedure [8]. For microscopic detection of Cryptosporidium, $5 \mathrm{mg}$ of smeared stool was left to air dry, fixed in alcohol and then stained with carbol fuchsin for 10 minutes. After that, smears were rinsed with tap water, decolorized in $1 \%$ sulfuric acid for 1 minute, washed with tap water and counter-stained with methylene blue for 5 minutes. Finally, stained smears were rinsed with tap water, air dried and then examined [6].

\section{Rapid test for Cryptosporidium and Giardia}

Rapid chromatographic immunological detection of Cryptosporidium and Giardia using the CerTest Biotec (Zaragoza, Spain) rapid card was carried out using stool samples according to the manufacturer's instructions [9].

\section{Fecal occult blood}

Fecal occult blood (FOB) using Hemosure ${ }^{\circledR}$ (WHPM Inc., Irwindale, CA) was investigated according to the manufacturer's procedure [10].

\section{Statistical analysis}

Statistical analysis was performed using Statistical Package for the Social Sciences (SPSS), version 20 (IBM Corp., Armonk, NY). Demographic data and categorical variables were analysed by descriptive analysis. The chi-square $\left(\chi^{2}\right)$ test was used to analyse the level of significant association between sociodemographic variables and intestinal parasitic infection. A P value $<.05$ was considered statistically significant.

\section{Results}

Of the 500 participants, the number of overall samples that fulfilled the requirements was 355 , while the total number of infected cases with intestinal parasites was $22.3 \%$ (79/355) from 10 nationalities with no significant difference $(\mathrm{P}>.05)$, as shown in Table 1 . 


\section{Cureus}

\begin{tabular}{|c|c|c|c|c|}
\hline \multirow{2}{*}{ Nationality } & \multirow{2}{*}{$\begin{array}{l}\text { Total } \\
\text { N (\%) }\end{array}$} & \multicolumn{3}{|c|}{ Positive cases } \\
\hline & & $\mathrm{n}$ & $\%(\mathrm{~N}=355)$ & $\%(n=79)$ \\
\hline Bangladeshi & $73(20.6)$ & 21 & 5.9 & 26.6 \\
\hline Indian & $61(17.2)$ & 18 & 5.1 & 22.8 \\
\hline Pakistani & $48(11.0)$ & 7 & 2.0 & 8.9 \\
\hline Yemeni & 39 (13.5) & 8 & 2.3 & 10.1 \\
\hline Egyptian & $35(4.8)$ & 5 & 1.4 & 6.3 \\
\hline Sudanese & $27(6.5)$ & 3 & 0.8 & 3.8 \\
\hline Indonesian & $23(9.9)$ & 5 & 1.4 & 6.3 \\
\hline Ethiopian & $18(5.1)$ & 4 & 1.1 & 5.1 \\
\hline Fillipino & $17(7.6)$ & 6 & 1.8 & 7.6 \\
\hline Nepal & $14(3.9)$ & 2 & 0.6 & 2.5 \\
\hline Total & $355(100)$ & 79 & 22.3 & 100 \\
\hline
\end{tabular}

\section{TABLE 1: Nationalities of infected cases}

$X^{2}=10.76, P>.05$

As illustrated in Table 2, most participants were males (93\%, 330/355), while the remaining 7\% (25/355) were females; however, the prevalence rate was higher in females $(7 / 25,28 \%)$ than males $(72 / 330,21.8 \%)$, but without a significant difference $(\mathrm{P}>.05)$.

\begin{tabular}{|c|c|c|c|}
\hline Gender & Positive & Negative & Total \\
\hline Male & 72 & 258 & 330 \\
\hline Female & 7 & 18 & 25 \\
\hline Total & 79 & 276 & 355 \\
\hline
\end{tabular}

\section{TABLE 2: Gender and infection}

$X^{2}=0.513, P>.05$

The results revealed that the majority (67.1\%) were aged $20-39$ years, representing about $80 \%$ of the infected cases with a significance difference $(\mathrm{P}<.05)$ as shown in Table 3 . 


\section{Cureus}

\begin{tabular}{|c|c|c|c|}
\hline \multirow{2}{*}{ Age group (years) } & Positive & Negative & Total \\
\hline & $n(\%)$ & n (\%) & $\mathrm{N}(\%)$ \\
\hline $20-29$ & $45(57.0)$ & 93 (33.7) & 138 (38.9) \\
\hline $30-39$ & $19(24.1)$ & $81(29.3)$ & $100(28.2)$ \\
\hline $40-49$ & 12 (15.2) & 59 (21.4) & $71(20.0)$ \\
\hline $50-60$ & $3(3.8)$ & $43(15.6)$ & $46(13.0)$ \\
\hline Total & $79(100)$ & $276(100)$ & $355(100)$ \\
\hline
\end{tabular}

\section{TABLE 3: Distribution of infection according to age group}

$X^{2}=16.9, P<.05$

As shown in Table 4, out of the 79 infected cases, 68 (86.1\%) were infected with one parasite including protozoa (41.8\%) and helminths (44.3\%), while the remaining $13.9 \%$ were infected with mixed infections. The common prevalent intestinal protozoan parasite (including mixed infections) was Blastocystis hominis (16, 20.3\%), followed by Endolimax nana (12, 15.2\%), both Entamoeba coli and Giardia lamblia at 7.6\% (6), and Entamoeba histolytica (3, 3.8\%). Using both the permanent staining and the rapid diagnostic test, none of the fecal samples reacted positively for Cryptosporidium parasite. Seven different helminth parasites were detected in this study, of which five were nematodes. The most common helminth parasite, causing mixed infection, was Trichuris trichiura (23, 29.1\%), followed by A. lumbricoides (8, 10.1\%) and hookworm (5, 6.3\%). There were two positive cases of Strongyloides stercoralis, Schistosoma mansoni and Hymenolepis nana. Enterobius vermicularis adult worms were detected during physical examination in only one sample. There were significant differences in prevalence only among E. nana and T. trichiura $(\mathrm{P}<.05)$. 


\section{Cureus}

\begin{tabular}{|c|c|c|c|c|c|c|c|c|c|c|}
\hline Parasites & $\begin{array}{l}\text { Bangladeshi } \\
(\mathrm{n}=73)\end{array}$ & $\begin{array}{l}\text { Indian } \\
(n=61)\end{array}$ & $\begin{array}{l}\text { Pakistani } \\
(\mathrm{n}=48)\end{array}$ & $\begin{array}{l}\text { Yemeni } \\
(\mathrm{n}=39)\end{array}$ & $\begin{array}{l}\text { Egyptian } \\
(n=35)\end{array}$ & $\begin{array}{l}\text { Sudanese } \\
(\mathrm{n}=27)\end{array}$ & $\begin{array}{l}\text { Indonesian } \\
(\mathrm{n}=23)\end{array}$ & $\begin{array}{l}\text { Ethiopian } \\
(\mathrm{n}=18)\end{array}$ & $\begin{array}{l}\text { Filipino } \\
(\mathrm{n}=17)\end{array}$ & $\begin{array}{l}\text { Nepali } \\
(n=14)\end{array}$ \\
\hline \multicolumn{11}{|l|}{$\begin{array}{l}\text { Single protozoa } \\
\text { infection (33) }\end{array}$} \\
\hline $\begin{array}{l}\text { Blastocystis hominis } \\
\text { (10) }\end{array}$ & 2 & 1 & 1 & 2 & 1 & 0 & 1 & 1 & 1 & 0 \\
\hline Endolimax nana (10) & 5 & 2 & 1 & 1 & 0 & 0 & 0 & 1 & 0 & 0 \\
\hline Entamoeba coli (6) & 0 & 1 & 1 & 1 & 1 & 1 & 0 & 0 & 1 & 0 \\
\hline Giardia lamblia (4) & 1 & 1 & 1 & 0 & 0 & 0 & 1 & 0 & 0 & 0 \\
\hline $\begin{array}{l}\text { Entamoeba histolytica } \\
\text { (3) }\end{array}$ & 0 & 1 & 0 & 1 & 1 & 0 & 0 & 0 & 0 & 0 \\
\hline \multicolumn{11}{|l|}{$\begin{array}{l}\text { Single helminth } \\
\text { infection (35) }\end{array}$} \\
\hline Trichuris trichiura (21) & 7 & 7 & 2 & 1 & 0 & 1 & 1 & 1 & 1 & 0 \\
\hline $\begin{array}{l}\text { Ascaris lumbricoides } \\
\text { (8) }\end{array}$ & 1 & 2 & 1 & 1 & 1 & 0 & 1 & 1 & 0 & 0 \\
\hline Hookworm (2) & 1 & 0 & 0 & 0 & 0 & 0 & 1 & 0 & 0 & 0 \\
\hline $\begin{array}{l}\text { Strongyloides } \\
\text { stercoralis (2) }\end{array}$ & 0 & 1 & 0 & 0 & 0 & 0 & 0 & 0 & 1 & 0 \\
\hline $\begin{array}{l}\text { Enterobius vermicularis } \\
\text { (1) }\end{array}$ & 1 & 0 & 0 & 0 & 0 & 0 & 0 & 0 & 0 & 0 \\
\hline \multicolumn{11}{|l|}{ Mixed infections (11) } \\
\hline $\begin{array}{l}\text { B. hominis + } \\
\text { Chilomastix mesnili (3) }\end{array}$ & 1 & 0 & 0 & 0 & 0 & 0 & 0 & 0 & 1 & 1 \\
\hline $\begin{array}{l}\text { B. hominis + } \\
\text { hookworm (3) }\end{array}$ & 1 & 2 & 0 & 0 & 0 & 0 & 0 & 0 & 0 & 0 \\
\hline $\begin{array}{l}\text { E. nana + Hymenolepis } \\
\text { nana (2) }\end{array}$ & 1 & 0 & 0 & 1 & 0 & 0 & 0 & 0 & 0 & 0 \\
\hline $\begin{array}{l}\text { Iodamoeba bütschlii + } \\
\text { T. trichiura (2) }\end{array}$ & 0 & 0 & 0 & 0 & 0 & 0 & 0 & 0 & 1 & 1 \\
\hline $\begin{array}{l}\text { G. lamblia + } \\
\text { Schistosoma mansoni } \\
\text { (2) }\end{array}$ & 0 & 0 & 0 & 0 & 1 & 1 & 0 & 0 & 0 & 0 \\
\hline Total (79) & 21 & 18 & 7 & 8 & 5 & 3 & 5 & 4 & 6 & 2 \\
\hline
\end{tabular}

\section{TABLE 4: Prevalence of intestinal parasites based on nationalities}

Tables 1, 4 illustrate that the most frequent intestinal parasitic infections were reported in Bangladeshis (26.6\%) and Indians (22.8\%), while the least were among the Nepalis (2.5\%). There was no significant difference in relation to nationality and overall infection among workers $(\mathrm{P}>.05)$.

The highest prevalence of intestinal parasites was detected in food handlers, farmers and house guards $(22.8 \%, 15.2 \%$ and $12.7 \%$, respectively), while the lowest was among the house painters $(1.2 \%)$, as seen in Table 5. There was no significant difference between intestinal parasitic infection and occupation $(\mathrm{P}>.05)$. 


\section{Cureus}

\begin{tabular}{|c|c|c|c|}
\hline \multirow{2}{*}{ Occupation } & Positive & Negative & Total \\
\hline & $n(\%)$ & $n(\%)$ & $\mathrm{N}(\%)$ \\
\hline Food handler & $18(22.8)$ & 46 (16.7) & $64(18.0)$ \\
\hline Farmer & $12(15.2)$ & 41 (14.9) & $53(14.9)$ \\
\hline House guard & $10(12.7)$ & $33(12.0)$ & $43(12.1)$ \\
\hline Driver & $10(12.7)$ & $26(9.4)$ & $36(10.1)$ \\
\hline Electrician & $4(5.1)$ & $28(10.1)$ & $32(9.0)$ \\
\hline Puncture repair & $2(2.5)$ & $23(8.3)$ & $25(7.0)$ \\
\hline Cleaner & $4(5.1)$ & $17(6.2)$ & $21(5.9)$ \\
\hline Barber & $2(2.5)$ & $19(6.9)$ & $21(5.9)$ \\
\hline Car mechanic & $4(5.1)$ & $14(5.1)$ & $18(5.1)$ \\
\hline House maid & $5(6.3)$ & $9(3.3)$ & $14(3.9)$ \\
\hline Housewife & $2(2.5)$ & $9(3.3)$ & $11(3.1)$ \\
\hline House painter & $1(1.3)$ & $7(2.5)$ & $8(2.3)$ \\
\hline Carpenter & $2(2.5)$ & $3(1.1)$ & $5(1.4)$ \\
\hline Plumber & $3(3.8)$ & $1(0.4)$ & $4(1.1)$ \\
\hline Total & $79(100)$ & $276(100)$ & $355(100)$ \\
\hline
\end{tabular}

TABLE 5: Occupation and infection distribution

$X^{2}=11.10, P>.05$

For personal hygiene practices, $71.8 \%$ of the participants used to wash their hands before meals either with soap $(113,31.8 \%)$ or without soap $(142,40 \%)$, and $53(14.9 \%)$ rarely washed their hands, while the rest 47 (13.2\%) had the bad habit of not washing their hands. Almost $85 \%$ had a conduct of handwashing after using toilet (including 58\% without soap). Nevertheless, none of these findings reached a significance level at P > .05. Similar results were found for the habit of fingernail trimming and close contact with animals, as shown in Table 6. 


\section{Cureus}

\begin{tabular}{|c|c|c|c|}
\hline \multirow{2}{*}{ Practice } & Positive & Negative & Total \\
\hline & $n(\%)$ & $n(\%)$ & $\mathrm{N}(\%)$ \\
\hline \multicolumn{4}{|c|}{ Washing hands before meals* } \\
\hline Yes, with soap & $24(30.4)$ & 89 (32.2) & $113(31.8)$ \\
\hline Yes, without soap & $23(29.1)$ & $119(43.1)$ & $142(40.0)$ \\
\hline Rarely & $20(25.3)$ & $33(12.0)$ & $53(14.9)$ \\
\hline No & $12(15.2)$ & $35(12.7)$ & 47 (13.2) \\
\hline \multicolumn{4}{|c|}{ Washing hands after using toilet ${ }^{\star \star}$} \\
\hline Yes, with soap & $15(19.0)$ & $77(27.9)$ & $92(25.9)$ \\
\hline Yes, without soap & $36(45.6)$ & $171(62.0)$ & $207(58.3)$ \\
\hline Rarely & $28(35.4)$ & $28(10.1)$ & $56(15.8)$ \\
\hline \multicolumn{4}{|c|}{ Washing fresh vegetables/fruits ${ }^{\star \star \star}$} \\
\hline Yes & $19(24.1)$ & $124(44.9)$ & $143(40.3)$ \\
\hline Rarely & $42(53.2)$ & $131(47.5)$ & $173(48.7)$ \\
\hline No & $18(22.8)$ & $21(7.6)$ & $39(11.0)$ \\
\hline \multicolumn{4}{|c|}{ Fingernail trimming ${ }^{\star \star \star \star}$} \\
\hline Always & $12(15.2)$ & $87(31.5)$ & 99 (27.9) \\
\hline Sometimes & $50(63.3)$ & $149(54.0)$ & $199(56.1)$ \\
\hline Rarely & $17(21.5)$ & $40(14.5)$ & $57(16.1)$ \\
\hline \multicolumn{4}{|l|}{ Animal contact ${ }^{\star \star \star \star \star}$} \\
\hline Always & $31(39.2)$ & $156(56.5)$ & $187(52.7)$ \\
\hline Sometimes & $24(30.4)$ & $53(19.2)$ & $77(21.7)$ \\
\hline Rarely & $13(16.5)$ & $40(14.5)$ & $53(14.9)$ \\
\hline Never & $11(13.9)$ & $27(9.8)$ & $38(10.7)$ \\
\hline Total of each & $79(100)$ & 276 (100) & $355(100)$ \\
\hline
\end{tabular}

\section{TABLE 6: Personal hygiene practices and risk of infection}

${ }^{*} X^{2}=10.7,{ }^{\star *} X^{2}=29.6,{ }^{* \star *} X^{2}=19.9,{ }^{* \star \star *} X^{2}=8.7,{ }^{* \star * \star *} X^{2}=8.16, P<.05$

In the present study, it was found that the source of drinking water and eating at home were statistically significant factors in intestinal parasitic infections $(\mathrm{P}<.05)$, as shown in Table 7. 


\section{Cureus}

\begin{tabular}{|c|c|c|c|}
\hline \multirow{2}{*}{ Factor } & Positive & Negative & Total \\
\hline & $n(\%)$ & $n(\%)$ & $\mathrm{N}(\%)$ \\
\hline \multicolumn{4}{|c|}{ Regular source of drinking water ${ }^{\star}$} \\
\hline Bottled & $10(12.7)$ & $41(14.9)$ & $51(14.4)$ \\
\hline Filtered & $11(13.9)$ & $55(19.9)$ & 66 (18.6) \\
\hline Tap & $48(60.8)$ & $175(63.4)$ & $223(62.8)$ \\
\hline Wells & $10(12.7)$ & $5(1.8)$ & $15(4.2)$ \\
\hline \multicolumn{4}{|c|}{ Cooking and eating at home ${ }^{\star \star}$} \\
\hline Always & $17(21.5)$ & $174(63.0)$ & $191(53.8)$ \\
\hline Sometimes & $56(70.9)$ & $88(31.9)$ & $144(40.6)$ \\
\hline Rarely & $5(6.3)$ & $10(3.6)$ & $15(4.2)$ \\
\hline Never & $1(1.3)$ & $4(1.4)$ & $5(1.4)$ \\
\hline Total of each & $79(100)$ & $276(100)$ & 355 (100) \\
\hline
\end{tabular}

TABLE 7: Source of drinking water, food and risk of infection

${ }^{\star} X^{2}=18.6,{ }^{\star *} X^{2}=43.8, P<.05$

Data from Tables 8, 9 suggest higher percentages of parasitic infection in participants who are not aware about the parasites, and those who have arrived recently to Saudi Arabia, but without statistical difference (P $>$.05).

\begin{tabular}{|c|c|c|c|}
\hline & Positive & Negative & Total \\
\hline Aware & 5 & 27 & 32 \\
\hline Not aware & 31 & 136 & 167 \\
\hline Not sure & 43 & 113 & 156 \\
\hline Total & 79 & 276 & 355 \\
\hline
\end{tabular}

\section{TABLE 8: Awareness about intestinal parasites and infection}

$X^{2}=4.67, P>.05$ 


\section{Cureus}

\begin{tabular}{|c|c|c|c|}
\hline Year(s) & Positive (n) & Negative (n) & Total (n) \\
\hline$<1$ & 27 & 64 & 91 \\
\hline $1-5$ & 41 & 147 & 188 \\
\hline 6-10 & 6 & 36 & 42 \\
\hline$>10$ & 5 & 29 & 34 \\
\hline Total & 79 & 276 & 355 \\
\hline
\end{tabular}

\section{TABLE 9: Distribution of infection and years of residency in Saudi Arabia}

$\mathrm{X}^{2}=5.58, \mathrm{P}>.05$

Also, as see in Table 10, the infection rate among workers who live with their families $(12 / 112,10.7 \%)$ was less than that for those who live with other workers $(38 / 175,21.7 \%)$ or alone $(29 / 68,42.7 \%)$, with statistical difference $(\mathrm{P}<.05)$.

\begin{tabular}{|c|c|c|c|}
\hline Accommodation type & Positive & Negative & Total \\
\hline With other workers & 38 & 137 & 175 \\
\hline With family & 12 & 100 & 112 \\
\hline Alone & 29 & 39 & 68 \\
\hline Total & 79 & 276 & 355 \\
\hline
\end{tabular}

\section{TABLE 10: Accommodation type and infection distribution}

$\mathrm{X}^{2}=24.99, \mathrm{P}<.05$

Out of the 79 positive cases, 45 were positive for FOB, but without significant association ( $\mathrm{P}>.05)$, as illustrated in Table 11 .

\begin{tabular}{|c|c|c|c|}
\hline Occult blood & Positive & Negative & Total \\
\hline Positive & 45 & 163 & 208 \\
\hline Negative & 34 & 113 & 147 \\
\hline Total & 79 & 276 & 355 \\
\hline
\end{tabular}

\section{TABLE 11: Fecal occult blood and infection}

$\mathrm{X}^{2}=2.653, \mathrm{P}>.05$

\section{Discussion}

This is the first study regarding the prevalence of intestinal parasitic infections among non-Saudi workers in Bahrah, Saudi Arabia. The World Health Organization attributed the spreading of intestinal parasites to several factors such as the status of personal hygiene, level of environmental sanitation, drinking water sources, health education practices and control programs [11].

The prevalence of intestinal parasites in this study was $22.3 \%$ among 355 workers from seven Asian countries and three African countries. Previous studies conducted in Saudi Arabia reported various prevalence values. Studies in Riyadh, Al-Khobar, Jeddah, Al-Madina and Makkah reported a prevalence of 
$41.4 \%, 31.4 \%, 50.15 \%, 14.9 \%$ and $16 \%$, respectively [12-16]. Like our findings, all these previous studies found that the majority of workers were from Asian countries, within the age range of 20-40 years.

In this study, among the 14 detected parasites, seven were protozoa and seven were helminths, of which, five were nematodes, one cestoda and one trematoda. A total of 68 participants were positive with one intestinal parasite, while 11 were positive for two parasites. This is in agreement with previous studies in Saudi Arabia, where the single infection rate is higher than the mixed infection rate [12-16]. In the present study, none of the cases revealed Cryptosporidium parasites. This opportunistic coccidian parasite is common among immunocompetent and immunocompromised individuals and transmission occurs mainly by contaminated drinking water or swimming pools [17,18].

This study revealed that the major detected parasites were T. trichiura (29. 1\%), B. hominis (20.3\%), E. nana (15.2\%) and A. lumbricoides (10.1\%). Riyadh and Al-Khobar studies reported that T. trichiura, hookworm and A. lumbricoides were the most common isolated parasites [12,13]. On the other hand, a Jeddah study showed that the most common organisms were B. hominis, hookworm and T. trichiura, while in Al-Madina were $G$. lamblia, E. histolytica and T. trichiura, and in Makkah were B. hominis, E. coli and G. lamblia [14-16].

In the present study, at least one participant from each nationality (except Sudanese), was infected with $B$. hominis. Although this parasite is common worldwide, its pathogenicity is still uncertain with great controversy [19-23].

The detected pathogenic protozoa parasites (E. histolytica and G. lamblia) were detected in $11.4 \%$ of the infected cases, while nonpathogenic organisms (E. nana, E. coli, C. mesnili and I. bütschlii) were detected in more cases (29.1\%). Nonpathogenic intestinal protozoa should not be neglected and should considered as a health concern for the infected person, as their oral-fecal route of transmission is similar to the pathogenic organisms. This explains the detection of many mixed infections between pathogenic and nonpathogenic organisms leading to abdominal symptoms [24,25].

This study, consistent with previous studies in Saudi Arabia, revealed that the common detected parasites were protozoa and nematodes. The obvious explanation is the simple and direct mode of infection with these parasites. On the other hand, S. mansoni infection in two participants from Africa (Egypt and Sudan) was mainly contracted from their hometowns, as this fluke requires snail intermediate hosts, which are not found in Bahrah, to form the infective cercariae [26,27]. A similar observation was reported in previous studies in Jeddah and Al-Madina [14,15].

Although in this study the majority of workers were from Asian regions, there was not any statistically significant difference between nationality and the intestinal parasitic infection. That was not in agreement with previous studies [15]. A similar finding was observed regarding gender, age and occupation.

Findings from this study revealed that all investigated personal hygiene practices, source of drinking water/meals and type of accommodation showed significant association with intestinal parasitic infection. None of the previous studies on non-Saudi workers investigated these factors.

Results of this study indicated similar previous observations that there was no significant association between intestinal parasitic infection and positive FOB, but were inconsistent with another investigation [28-30].

\section{Conclusions}

This study provides insights about the prevalence of intestinal parasites and clarifies related factors among non-Saudi workers in Bahrah. The prevalence was slightly high (22.3\%) and was associated mainly with hygiene practices, individual habits and awareness. Among the positive cases, almost $86 \%$ were single infections and $14 \%$ mixed infections. Intestinal protozoa and nematodes were the most predominant parasites, followed by cestodes and trematodes.

These findings draw attention for the need of more awareness about diagnosis protocols, control of intestinal parasitic infection, in addition to personal hygiene, eating habits and lifestyle.

\section{Additional Information \\ Disclosures}

Human subjects: Consent was obtained by all participants in this study. Ethics and Research Committee of Faculty of Applied Medical Sciences, King Abdulaziz University issued approval 019-22. Animal subjects: All authors have confirmed that this study did not involve animal subjects or tissue. Conflicts of interest: In compliance with the ICMJE uniform disclosure form, all authors declare the following: Payment/services info: All authors have declared that no financial support was received from any organization for the submitted work. Financial relationships: All authors have declared that they have no financial relationships at present or within the previous three years with any organizations that might have an 
interest in the submitted work. Other relationships: All authors have declared that there are no other relationships or activities that could appear to have influenced the submitted work.

\section{Acknowledgements}

The author would like to thank the Faculty of Applied Medical Sciences and Special Infectious Agents Unit, King Fahd Medical Research Center at King Abdulaziz University in Jeddah, Saudi Arabia, for supporting this work.

\section{References}

1. Neglected tropical diseases. (2020). Accessed: April 17, 2020: https://www.who.int/neglected_diseases/diseases/en/.

2. Soil-transmitted helminth infections. (2020). Accessed: April 17, 2020: https://www.who.int/en/newsroom/fact-sheets/detail/soil-transmitted-helminth-infections.

3. Torgerson PR, Devleesschauwer B, Praet N, et al.: World Health Organization estimates of the global and regional disease burden of 11 foodborne parasitic diseases, 2010: a data synthesis. PLoS Med. 2015, 12:e1001920. 10.1371/journal.pmed.1001920

4. The Sixteenth Services Guide 2017: Makkah Al-Mokarramah region. (2017). Accessed: April 18, 2020: https://www.stats.gov.sa/sites/default/files/makkah_al-mokarramah_region_en.pdf.

5. Garcia LS, Arrowood M, Kokoskin E, et al.: Laboratory diagnosis of parasites from the gastrointestinal tract . Clin Microbiol Rev. 2017, 31:e00025-17. 10.1128/CMR.00025-17

6. World Health Organization: Bench Aids for the Diagnosis of Intestinal Parasites, Second Edition . World Health Organization, Geneva; 2019.

7. Wakid MH: Improvement of Ritchie technique by identifying the food that can be consumed pre-analysis . J Appl Sci Res. 2009, 5:293-296.

8. Para-Pak ${ }^{\circledR}$ trichrome stain. (2014). Accessed: March 18, 2019: https://www.meridianbioscience.com/uploads/400101_400112_pi.pdf.

9. CerTest Crypto+Giardia. (2013). Accessed: March 18, 2019: https://www.abacusdx.com/media/CerTest_Crypto_Giardia.pdf.

10. Hemosure ${ }^{\circledR}$ procedural manual. Accessed: March 18, 2019: https://www.hemosure.com/wpcontent/uploads/2013/10/Hemosure-Current-Procedure-Manual-11.14.16-Finalized.pdf.

11. Prevention and control of intestinal parasitic infections: WHO technical report series no. 749 . (1987). Accessed: April 18, 2019: https://apps.who.int/iris/bitstream/handle/10665/41298/WHO_TRS_749.pdf? sequence $=1$.

12. Abu Al-Saud AS: Faecal parasites in non-Saudi catering and domestic staff at the Riyadh military hospital . Saudi Med J. 1983, 4:259-262.

13. Abahussain NA: Prevalence of intestinal parasites among expatriate workers in Al-Khobar, Saudi Arabia . Middle East J Fam Med. 2005, 3:17-21.

14. Wakid MH: Distribution of intestinal parasites among food handlers in Jeddah, Saudi Arabia . J Parasitic Dis. 2006, 30:146-152.

15. Taha HA, Soliman MI, Banjar SA: Intestinal parasitic infections among expatriate workers in Al-Madina AlMunawarah, Kingdom of Saudi Arabia. Trop Biomed. 2013, 30:78-88.

16. Ahmed MA, Alam-Eldin YH, Eltaweel NA, Elmorsy S: Intestinal parasites detected during pre-employment stool examination at tertiary health care center in Makkah, Kingdom of Saudi Arabia. J Egypt Soc Parasitol. 2015, 45:367-373. 10.12816/0017580

17. WHO guidelines for drinking water quality, Cryptosporidium. (2006). Accessed: May 2, 2020: https://www.who.int/water_sanitation_health/gdwqrevision/cryptodraft2.pdf.

18. Peletz R, Mahin T, Elliott M, Montgomery M, Clasen T: Preventing cryptosporidiosis: the need for safe drinking water. Bull World Health Organ. 2013, 91:238-238A. 10.2471/BLT.13.119990

19. Aldahhasi W, Toulah F, Wakid MH: Evaluation of common microscopic techniques for detection of Blastocystis hominis. J Egypt Soc Parasitol. 2020, 50:33-40. 10.12816/JESP.2020.88748

20. Gentekaki E, Curtis BA, Stairs CW, et al.: Extreme genome diversity in the hyper-prevalent parasitic eukaryote Blastocystis. PLoS Biol. 2017, 15:e2003769. 10.1371/journal.pbio.2003769

21. Chen T, Chan C, Chen H, Fung C, Lin C, Chan W, Liu C: Clinical characteristics and endoscopic findings associated with Blastocystis hominis in healthy adults. Am J Trop Med Hyg. 2003, 69:213-216. 10.4269/ajtmh.2003.69.213

22. Yason JA, Liang YR, Png CW, Zhang Y, Tan KSW: Interactions between a pathogenic Blastocystis subtype and gut microbiota: in vitro and in vivo studies. Microbiome. 2019, 7:30. 10.1186/s40168-019-0644-3

23. Kesuma Y, Firmansyah A, Bardosono S, Sari IP, Kurniawan A: Blastocystis ST-1 is associated with irritable bowel syndrome-diarrhoea (IBS-D) in Indonesian adolescences. Parasite Epidemiol Control. 2019, 6:e0112. 10.1016/j.parepi.2019.e00112

24. Pagheh AS, Sharif M, Daryani A, et al.: A cross-sectional analysis of intestinal parasitic infections among the general population in north of Iran. J Infect Dev Ctries. 2018, 12:120-126. 10.3855/jidc.9512

25. Poulsen CS, Stensvold CR: Systematic review on Endolimax nana: a less well studied intestinal ameba . Trop Parasitol. 2016, 6:8-29. 10.4103/2229-5070.175077

26. Sulieman Y, Eltayeb RE, Pengsakul T, Afifi A, Zakaria MA, Khairala MA: Schistosomiasis as a disease and its prevalence in Sudan: an overview. J Coast Life Med. 2017, 5:129-133. 10.12980/jclm.5.2017J6-247

27. Othman AA, Soliman RH: Schistosomiasis in Egypt: a never-ending story? . Acta Trop. 2015, 148:179-190. 10.1016/j.actatropica.2015.04.016

28. Wakid MH: Fecal occult blood test and gastrointestinal parasitic infection. J Parasitol Res. 2010, 2010:434801. 10.1155/2010/434801

29. Ugwuoke H, Okonkwo B, Oshilonyah H, et al.: Faecal occult blood and intestinal parasites among patients attending outpatient clinic in Agbor, Delta State Nigeria. Arch Biomed Sci Health. 2013, 1:20-28. 


\section{Cureus}

30. Jada S, Jayakumar K, Vinoth R, Ravichandran R, Sivanandham N, Seeda C: Detection of fecal occult blood among patients with intestinal parasitic infections attending a tertiary care centre. J Dis Glob Health. 2015, 5:73-77. 